\section{Constitution and Properties of Laccase}

IT was shown that laccase, which had been inactivated by cyanide under certain conditions, could be almost completely re-activated by cupric ions, whereas other metals were ineffective'. Further evidence will be presented here to show that copper is an essential constituent of this enzyme. Laccase was purified by the method of $D$. Bertrand ${ }^{2,3}$. At each successive stage of purification the enzyme activity was measured in the manner previously described $^{1}$, and copper and manganese were estimated by microchemical methods, 5. Manganese disappears after the first steps of purification; the copper content increases with the $Q_{\mathrm{O}_{2}}$ and remains proportional to activity in all fractions up to the purest preparation having $Q_{\mathrm{O}_{2}} 30,000$ in presence of paraphenylene diamine (Fig. 1).

In recent papers, D. Bertrand has described three important properties of laccase which will be reexamined here. It is elaimed that the activity of this enzyme is much more sensitive than that of other enzymes to small variations of $p \mathrm{H}^{6}$. For example, with pyrogallol as substrate, the 'relative $Q_{\mathrm{C}_{2}}$ ' is said to fall from 10,000 to 1,500 when the $p H$ changes from $6 \cdot 5$ to $7 \cdot 0$. On repeating these experiments, I found that the sensitivity of laccase to $p H$ variations is no greater than is generally the case with enzymes, and that optimum activity is observed at $p \mathrm{H} 7 \cdot 4$ with pyrogallol and at $p \mathrm{H} 7 \cdot 0$ with paraphenylene diamine (Fig. 2).

Furthermore, D. Bertrand found that laccase, like cytochrome oxidase, has the property of oxidizing cytochrome $c^{7,8}$ and cystein ${ }^{9}$, and this led him to believe that the two enzymes are probably closely related. However, if laccase is added to reduced cytochrome $c$ and the mixture shaken in air, no spectroscopic change occurs. The oxidation of cyto. chrome $c$ has also been studied manometrically in the way described by D. Bertrand ${ }^{7,8}$. Thus the oxygen uptake at $20^{\circ} \mathrm{C}$. of a system consisting of laccase and $10 \mathrm{mgm}$. hydroquinone in $3.3 \mathrm{ml}$. phosphate buffer, $p H 7 \cdot 1$, was only increased by 5-7 per cent by the addition of $0.2 \mathrm{ml}$. of 1 per cent cytochrome c. Since, however, the quantity of cytochrome $c$ used in such experiments is at least thirty times greater than the quantity of laccase (assuming that pure laccase has a $Q_{\mathrm{O}_{2}}$ of 20,000 in the oxidation of hydroquinone), the resulting increase in oxygen

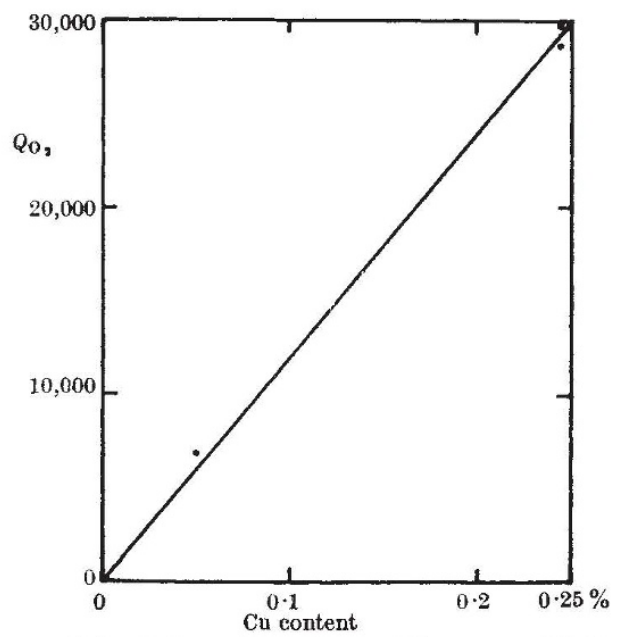

Fig. 1. Relation between the activity of the enzyme $\left(Q_{0}\right)$ and

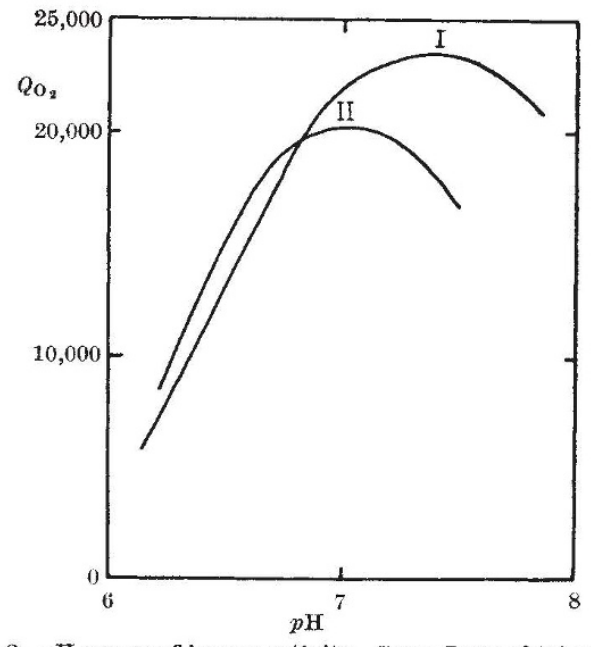

Fig. 2. $p \mathrm{H}$ curves of laccase activity. Curve I was obtained with pyrogallol and curve II with paraphenylene diamine

uptake is insignificant, and there is thus no indication that cytochrome $c$ is oxidized by laccase.

The methyl ester of cystein, as well as cystein itself, is said to be oxidized by laccase ${ }^{9}$. It was claimed that this oxidation has the unusual feature that the $p H$ activity curve shows two well-marked optima at $p \mathrm{H} 6 \cdot 7$ and $7 \cdot 45$, at which the rate of oxygen uptake is 31 and 27 per cent respectively of that by hydroquinone at $p H \mathbf{H} \cdot \mathbf{3 5}$. On repeating these experiments in Barcroft manometers, it was found that cystein was not oxidized at all by laccase, even after shaking for thirty minutes. The slow rate of oxygen uptake observed with laccase and eystein methyl ester represented only 5-8 per cent of that found with laccase and paraphenylene diamine. Moreover, a study of the effect of $p H$ on this slow oxidation revealed not two optima, but one at $7 \cdot 1$, and the $p H$ activity curve was of the usual type. As laccase does not oxidize cystein, and as its effect on the methyl ester is very small, the conclusion that cystein can be oxidized directly by laccase is not justified.

Molteno Institute,

A. TISSIÈres

University of Cambridge.

${ }^{1}$ Tissières, A., Nature, 162, 340 (1948).

2 Bertrand, D., Bull. Soc. Chim. biol., 26, 40 (1944).

${ }^{3}$ Bertrand, D., Ann. Inst. Pasteur, 73, 266 (1947).

'Eden, A., and Green, H. H., Biochem. J., 34, 1203 (1940).

"Wiese, A. C., and Johnson, B. C., J. Biol. Chem., 127, $203(1939$.

- Bertrand, D., Bull. Soc. Chim. biol., 26, 45 (1944).

${ }^{7}$ Bertrand, D., Belval, H., and Legrand, Gilberte, C.R. Acad. Sci. Paris, 223, 1189 (1946).

$s$ Bertrand, D., Belval, H., and Legrand, Gilberte, Bull. Soc. Chim. biol., 29,607 (1947).

- Bertrand, D., Bull. Soe. Chim. biol., 29, 608 (19t7).

\section{Investigations with Radioactive Penicillin}

MucH of the published data regarding the mode of action of penicillin is necessarily concerned with secondary effects on bacteria, for example, rate of killing under different conditions, morphological changes, etc. By use of radioactive penicillin, it should be possible to find out directly something of the nature of the primary reaction between penicillin and the cell.

In a previous communication ${ }^{1}$, we have described attempts to measure the amount of penicillin involved in the killing of bacteria, which gave no positive 